\title{
Role of the Novel Hsp90 Co-Chaperones in Dynein Arms' Preassembly
}

\author{
Hanna Fabczak * and Anna Osinka \\ Laboratory of Cytoskeleton and Cilia Biology, Nencki Institute of Experimental Biology, Polish Academy of \\ Sciences, 3 Pasteur Str., 02-093 Warsaw, Poland; a.osinka@nencki.edu.pl \\ * Correspondence: h.fabczak@nencki.edu.pl; Tel.: +48-22-5892-317
}

Received: 8 November 2019; Accepted: 4 December 2019; Published: 7 December 2019

\begin{abstract}
The outer and inner dynein arms (ODAs and IDAs) are composed of multiple subunits including dynein heavy chains possessing a motor domain. These complex structures are preassembled in the cytoplasm before being transported to the cilia. The molecular mechanism(s) controlling dynein arms' preassembly is poorly understood. Recent evidence suggests that canonical R2TP complex, an Hsp-90 co-chaperone, in cooperation with dynein axonemal assembly factors (DNAAFs), plays a crucial role in the preassembly of ODAs and IDAs. Here, we have summarized recent data concerning the identification of novel chaperone complexes and their role in dynein arms' preassembly and their association with primary cilia dyskinesia (PCD), a human genetic disorder.
\end{abstract}

Keywords: Hsp90; R2TP; DNAAFs; SPAG1; WDR92; ODA; IDA; dynein arm preassembly

\section{Introduction}

Motile cilia are evolutionarily conserved, microtubule-based organelles present in numerous types of organisms from protists to mammals. These thin (approximately $0.2 \mu \mathrm{m}$ in diameter) but long (usually up to $20 \mu \mathrm{m}$, and, in the case of some insect sperm flagella, more than $100 \mu \mathrm{m}$ [1]) organelles jut from the apical cell surface and are crucial for the functioning and asymmetric arrangement of the major visceral body organs. In humans, motile cilia are usually assembled in large numbers by the epithelial cells lining the trachea, oviduct, ventricular system of the brain and the spinal cord. The coordinated planar beating of motile cilia generates movement that facilitates the clearing of mucus out of the airways, and supports transport of the ovum in the oviduct and circulation of cerebrospinal fluid in the brain ventricles. Single, long cilia, called flagella, enable movement of the sperm cells [2]. Specific motile cilia, so-called nodal cilia, are present in the embryonic node. Nodal cilia beat circularly, generating a leftward-directed fluid flow [3,4], and play a critical role in the generation of the left-right asymmetry of the arrangement of the major visceral body organs [5].

The scaffold of the motile cilium, the axoneme, is composed of nine outer microtubule doublets with docked multiprotein complexes and a pair of central microtubules with attached projections $(9+2$ structure). The outer doublet complexes, such as nexin-dynein regulatory complexes (N-DRC), radial spokes (RS1-RS3) and axonemal dynein arms, repeat periodically, forming a characteristic pattern along the entire cilium length with a basic, 96-nm unit. Each 96-nm repeat contains four ODAs, seven IDAs, three RSs, N-DRC, and other minor complexes [6]. Mammalian nodal cilia lack the central pair of microtubules, radial spokes, and IDAs (9+0 organization) [3] (Figure 1). 


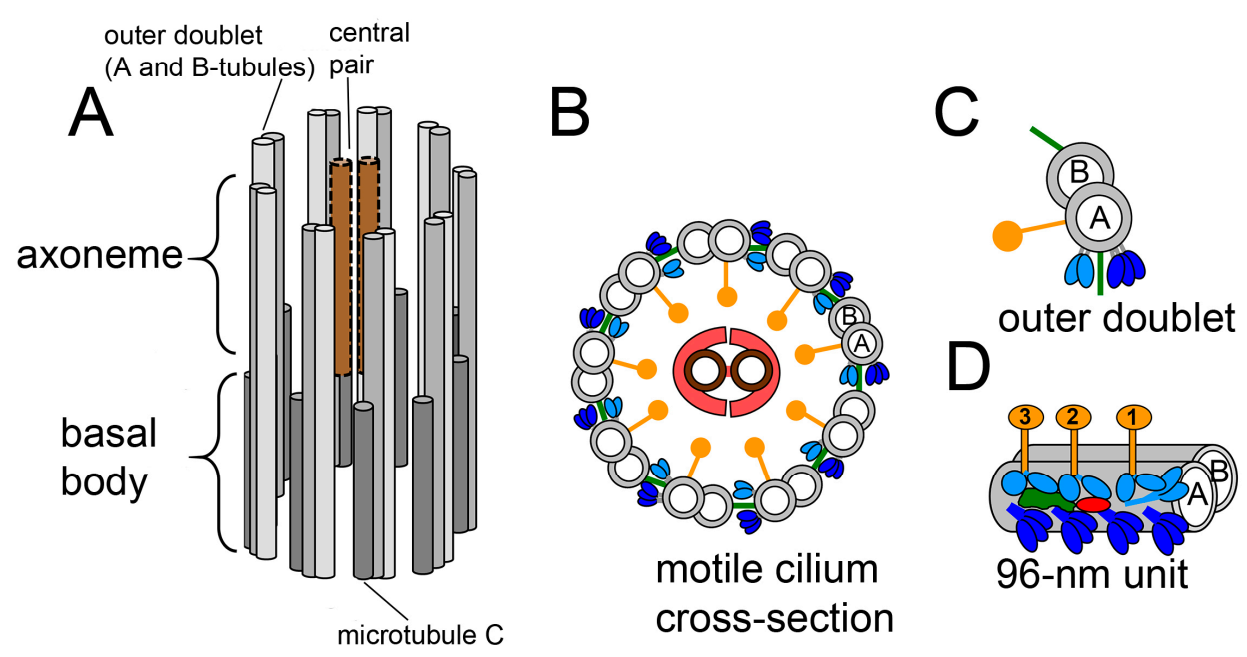

Figure 1. Schematic representation of motile cilia structure. A: Longitudinal view of the cilium. The nine peripheral doublet microtubules (gray) are a continuation of two out of three microtubules of the basal body microtubular triplets surrounding the central pair (brown); B: The cross-section of the axoneme from Tetrahymena thermophila shows nine doublet microtubules (A- and B-tubules, gray) surrounding a central pair of singlet microtubules (brown) with projection (orange). Attached to the doublet microtubules are the radial spokes (yellow), inner dynein arm (IDA, light blue), outer dynein arm (ODA, dark blue), nexin-dynein regulatory complex (NDRC, green) and modifier of the inner arms complex (MIA complex, red); C: The view of the doublet microtubule with attached macrocomplexes. (description as in B); D: The organization of macro-complexes within the 96-nm unit (description as in B) [7].

Dynein arms facilitate the ATP-dependent microtubule sliding, which drives the ciliary movement [8]. Both outer dynein arms (ODAs) and inner dynein arms (IDAs) are large multi-subunit complexes that differ in their protein composition and motor properties. ODAs contain three (in Stramenopiles, Alveolata, and Rhizaria) or two (in metazoans and excavates) motor-domains containing dynein heavy chains (DHC) [9], two intermediate chains (IC1, IC2 in Chlamydomonas and DNAI1, DNAI2 in vertebrate) and about 10 light chains (LCs). ODAs are attached to the microtubules via ODA docking complexes (ODA-DCs) [10,11].

IDAs, present in one 96-nm unit, differ in their protein composition and likely function. Only IDA $\mathrm{f} / 11$ contains two heavy chains, while the other IDAs $(a, b, c, d, e, g)$ have one heavy chain, specific to each arm. IDA f/11, in addition to two dynein heavy chains, different from chains of ODAs or/and monomeric IDAs, consists of at least seven additional subunits named, according to their size, intermediate chains (IC: IC140, IC138, and IC97) and light chains (LC: Tctex1, Tctex2b, LC7a, LC7b, and LC8) [10].

A growing number of studies indicate that the molecular mechanismcontrolling assembly of ODAs and IDAs, and their targeting to cilia, is evolutionarily conserved. Subunits of the dynein arms are synthesized, and dynein arm complexes are preassembled in the cytoplasm. The pre-assembled dynein arms are transported to cilia by intraflagellar transport (IFT) [12-15]. At least a dozen proteins known as axonemal dynein assembly factors (DNAAFs) participate in the preassembly of ODA and IDA [16-18]. Interestingly, DNAAFs were discovered during the search for the causative mutations in individuals affected by primary ciliary dyskinesia (PCD), generally an autosomal recessive disease that manifests by defective cilia/flagella motility.

DNAAFs interact with and chaperone Hsp70 (heat shock protein 70), Hsp90 (heat shock protein 90), and Hsp90 co-chaperones, R2TP (RuvB-like protein 1 (RuvBL1), RuvB-like protein 2 (RuvBL2), RNA polymerase-associated protein 3 (RPAP3), and PIH1 domain-containing protein 1 (PIH1D1)) and R2TP-like complexes $[16,19]$. Here we have summarized recent advances in the identification of potential components of R2TP-like complexes and in understanding their role in dynein arms' preassembly in several model organisms and in the etiology of the primary ciliary dyskinesia (PCD). 


\section{Hsp90 and Its Co-Chaperones}

Hsp90 is a widespread molecular chaperone important for protecting cells from stress, such as high temperatures [20]. However, Hsp90 regulates many biological processes such as cell-cycle progression, telomere maintenance, apoptosis, mitotic signal transduction, vesicle-mediated transport, immunity, and targeted protein degradation [21]. Hsp90 functions in vivo as the core component of a dynamic set of multiprotein complexes, collaborating with a plethora of proteins or co-chaperones [22]. An important Hsp90 co-chaperone is an R2TP complex that assists Hsp90 in the assembly of large protein complexes (L7Ae ribonucleoproteins, U5 small nuclear ribonucleoprotein, RNA polymerase II, phosphatidylinositol-3-kinase-related proteins). The R2TP complex also participates in the pre-assembly of the dynein arms [23].

\subsection{Composition of R2TP Complex}

The R2TP complex was discovered in Saccharomyces cerevisiae as an Hsp90 co-chaperone [24]. In humans, the canonical R2TP complex consists of a hexamer composed of two AAA + ATPases related proteins, RuvBL1/Pontin and RuvBL2/Reptin, and a heterodimer composed of RPAP3 and PIH1D1 (Figure 2). The RPAP3-PIH1D1 heterodimer is an integral and specific component of R2TP and likely regulates the enzymatic activity of RuvBL1 and RuvBL2 [25]. The RuvBL1 and RuvBL2 AAA ATPases, due to their enzymatic activity, form the catalytic component of the R2TP complex, probably acting not only as co-chaperone but also as a chaperone [26].

Table 1. List of proteins forming R2TP and other complexes involved in the preassembly of axonemal dynein arms.

\begin{tabular}{|c|c|c|c|c|c|c|c|}
\hline $\begin{array}{l}\text { Human } \\
\text { Protein }\end{array}$ & Aliases & $\begin{array}{l}\text { Protein Accession } \\
\text { Number }\end{array}$ & $\begin{array}{c}\text { Protein } \\
\text { Size (kDa) }\end{array}$ & $\begin{array}{l}\text { Localization } \\
\text { in Cell }\end{array}$ & Domains & $\begin{array}{l}\text { * Chaperone, Co-Chaprone and } \\
\text { DNAAFs Interaction }\end{array}$ & PCD \\
\hline RuvBL1, & Pontin & Q9Y265 & 50 & DynAPs & & $\begin{array}{l}\text { Hsp90, RuvBL2, PIH1D1, RPAP3, } \\
\text { WDR92, SPAG1 }\end{array}$ & - \\
\hline RuvBL2 & Reptin & Q9Y230 & 51 & DynAPs & & $\begin{array}{l}\text { RuvBL1, PIH1D1, RPAP3, } \\
\text { WDR92 }\end{array}$ & - \\
\hline RPAP3 & HSpagh & Q9H6T3 & 75 & - & $\begin{array}{c}\text { TPR- } \\
\text { RPAP3-C-ter }\end{array}$ & $\begin{array}{c}\text { Hsp70, Hsp90, RuvBL1, RuvBL2, } \\
\text { PIH1D1, WDR92, }\end{array}$ & \\
\hline PIH1D1 & & Q9NWS0 & 32 & - & PIH1, CS & $\begin{array}{l}\text { Hsp90, RuvBL1, RuvBL2; } \\
\text { RPAP3, WDR92, DNAAF4 }\end{array}$ & - \\
\hline PIH1D2 & & Q8WWB5 & 39.4 & - & PIH1, CS & $\begin{array}{c}\text { RuvBL1; } \\
\text { RuvBL2, SPAG1 }\end{array}$ & - \\
\hline WDR92 & Monad & Q96MX6 & 39.7 & DynAPs & WD40 & $\begin{array}{c}\text { RuvBL1, RuvBL2; RPAP3, } \\
\text { PIH1D1, DNAAF1, DNAAF4, } \\
\text { SPAG1 }\end{array}$ & \\
\hline SPAG1 & & Q07617 & 103.6 & DynAPs & $\begin{array}{c}\text { TPR, } \\
\text { RPAP3-C-ter }\end{array}$ & $\begin{array}{c}\text { Hsp70, Hsp90, RuvBL1, RuvBL2, } \\
\text { PIH1D2, WDR92, DNAAF2, } \\
\text { DNAAF4, DNAAF5, DNAAF6 }\end{array}$ & $\begin{array}{l}\text { MIM:615505 } \\
{[28]}\end{array}$ \\
\hline DNAAF1 & $\begin{array}{l}\text { LRRC50/ } \\
\text { ODA7 }\end{array}$ & Q8NEP3 & 40 & cytoplasm & LRR & $\begin{array}{c}\text { Hsp90, } \\
\text { RuvBL1, RuvBL2, }\end{array}$ & $\begin{array}{l}\text { MIM:613193 } \\
{[29]}\end{array}$ \\
\hline DNAAF2 & $\begin{array}{l}\text { KTU/ } \\
\text { PF13 }\end{array}$ & Q9NVR5 & 91 & DynAPs & PIH1, CS & $\begin{array}{c}\text { HSP70, HSP90, RuvBL1, RuvBL2, } \\
\text { DNAAF4 }\end{array}$ & $\begin{array}{c}\text { MIM:612518 } \\
{[16]}\end{array}$ \\
\hline DNAAF4 & DYX1C1 & Q86X45 & 48.5 & DynAPs & TPR, CS & $\begin{array}{c}\text { Hsp70, Hsp90, DNAAF4 } \\
\text { RuvBL1, RuvBL2 } \\
\text { DNAAF2 }\end{array}$ & $\begin{array}{c}\text { MIM:615482 } \\
{[30]}\end{array}$ \\
\hline DNAAF5 & HEATR2 & Q86Y56 & 93.5 & DynAPs & HEAT_type_2 & DNAAF2, SPAG1, & $\begin{array}{c}\text { MIM:614874 } \\
{[31,32]}\end{array}$ \\
\hline DNAAF6 & PIH1D3 & Q9NQM4 & 24 & DynAPs & PIH1, CS & $\begin{array}{l}\text { Hsp70, Hsp90, DNAAF1, } \\
\text { DNAAF2, DNAAF3 }\end{array}$ & $\begin{array}{l}\text { CILD36 } \\
{[33,34]}\end{array}$ \\
\hline DNAAF7 & ZMYND10 & O75800 & 50 & DynAPs & Znf_MYND & $\begin{array}{c}\text { Hsp90, Hsc70 RuvBL2, LRRC6, } \\
\text { DNAAF4, }\end{array}$ & $\begin{array}{c}\text { MIM:615444 } \\
{[35,36]}\end{array}$ \\
\hline LRRC6 & Seahorse & Q86X45 & 54 & DynAPs & LRR, CS & RuvBL1, RuvBL2 DNAAF4, & $\begin{array}{l}\text { MIM:614935 } \\
{[37-39]}\end{array}$ \\
\hline
\end{tabular}

TPR domain (tetratricopeptide repeat), CS domain (CHORD-containing proteins and SGT1), LRRC (Leucine-Rich Repeat-Containing), PIH1 domain (protein interacting with heat shock protein 90), WD40 repeat protein, RPAP3-Cter domain. MIM (Mendelian Inheritance in Man, Phenotype MIM number; https://omim.org/). * Summary of main experimental data from biochemical analysis (e.g. co-immunoprecipitation, yeast two-hybrid system, protein-protein cross-link assays, GST-pulldown) in different model organisms. 
A

R2TP
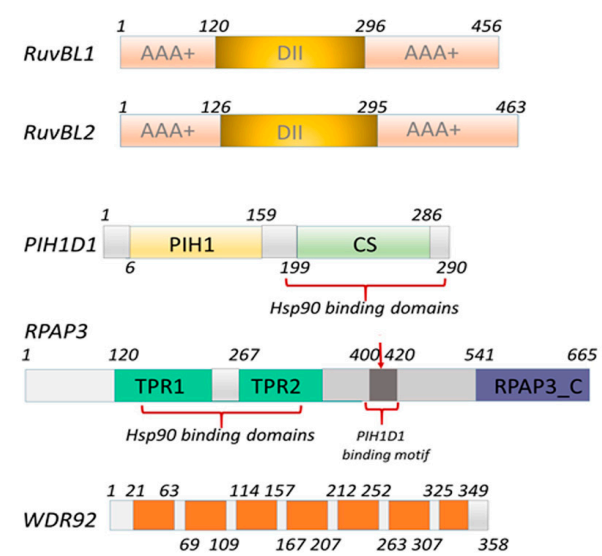

B

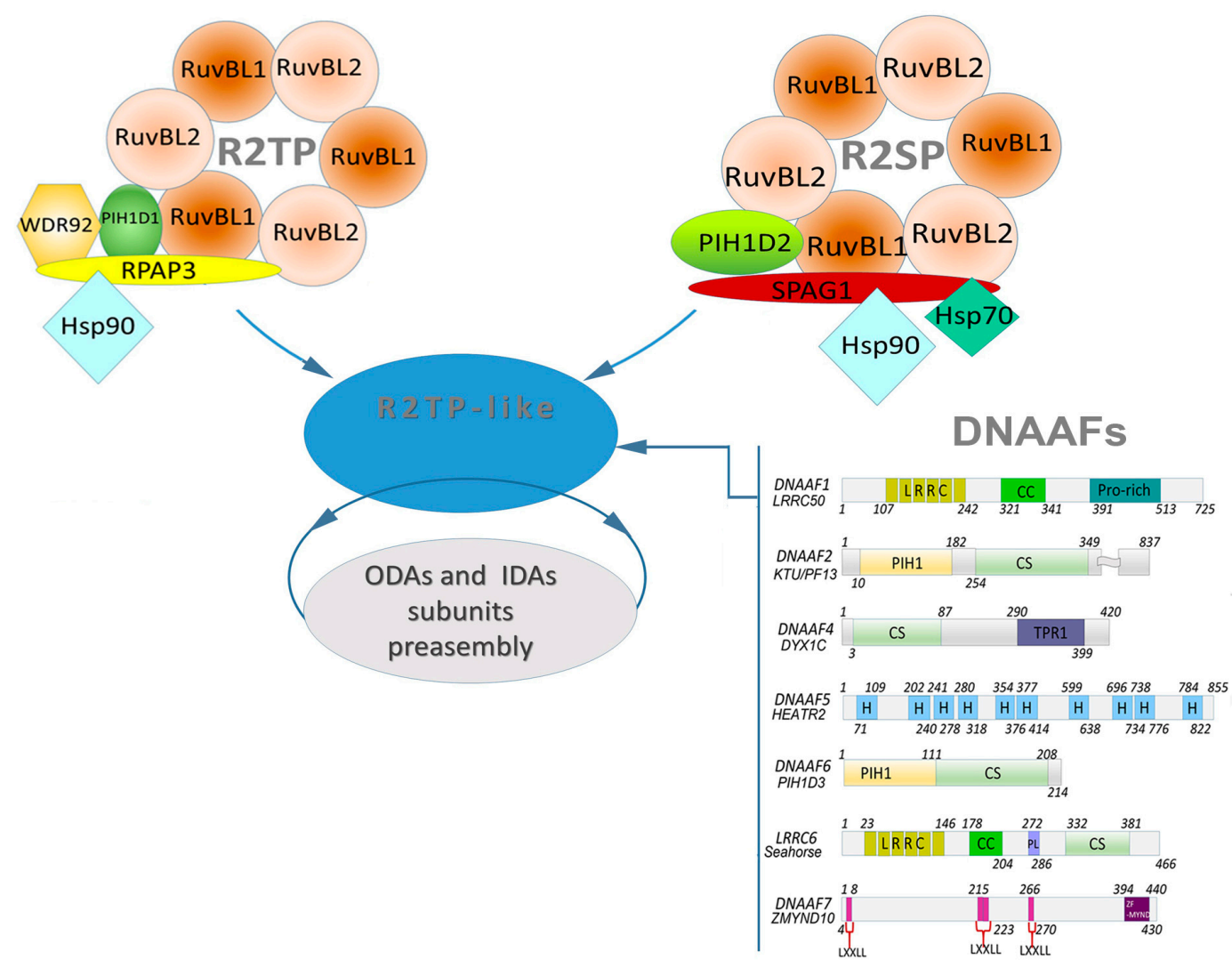

Figure 2. Proposed model of RT2P-like complex structure and function. A: Domain structure of human R2TP (RuvBL1, RuvBL2, PIH1D1, RPAP3, WDR92) and R2SP (RuvBL1, RuvBL2, SPAG1). B: Diagram illustrating the possible function of an RT2P-like complex that includes R2TP and/or R2SP and dynein axonemal assembly factors (DNAAFs) involved in the process of pre-assembly of axonal dynein arms. DNAAFs, together with chaperones (Hsp90, Hsp70), co-chaperons R2TP and R2SP, and axonemal dyneins form a cytoplasmic organelle-like structure called DynAPs (dynein axonemal particles) [27], for details, see Table 1. Domain organization: RPAP3 (RPAP3-Cter domain); TPR (tetratricopeptide repeat); PHI1 (protein interacting with heat shock protein 90); CS (CHORD-containing proteins and SGT1); WD (WD40 repeat); LRRC (Leucine-Rich Repeat-Containing); H (HEAT Repeat-Containing); CC (coiled-coil domain); LxxLL (Leu-Xaa-Xaa-Leu-Leu) motif; ZF-MYND (Mynd-type zinc finger domain). 
The N-terminal region of PIH1D1 (Figure 2) has the conserved PIH1 domain (protein interacting with heat shock protein 90) known to mediate the binding of proteins containing a specific motif phosphorylated by casein kinase 2 (CK2) [40-42]. The C-terminal region of PIH1D1 has a CS domain (ㄷHORD-containing proteins and $\underline{\mathrm{S}} \mathrm{GT1}$ ), also present in other Hsp90 co-chaperones (such as p23) [43]. The C-terminal domain (Pih1D1-C-ter), comprising the CS domain, mediates direct interactions between PIH1D1 and RPAP3 and between RuvBL1 and RuvBL2 [42]. RPAP3 (Figure 2) possesses a C-terminal domain of unknown function (RPAP3-C-ter) and two tandem N-terminal TPRs (tetratricopeptide repeats) domains. The TPR domains enable binding of RPAP3 to Hsp70 [44,45] and Hsp90 (more precisely, to the C-terminal fragment of Hsp90 containing a conserved MEEVD motif/sequence) (Figure 2) $[19,40,46]$.

\subsection{R2TP Complexes in the Dynein Arm Assembly}

The first indications that RuvBL1 and RuvBL2 could play a role in the formation of motile cilia came from studies in Chlamydomonas. The genome-wide transcriptional analyses revealed that RuvBL1 and RuvBL2 are strongly upregulated during the regeneration of Chlamydomonas flagella [47]. Later, using immunofluorescence analyses it was shown that, in embryos of Danio rerio, RuvBL1 and RuvBL2 is present in cells assembling motile cilia (extra-renal tissues, pronephric tubule cells, Kupffer's vesicle, the neural tube) [15]. Danio rerio mutants with loss-of-function mutation in genes encoding RuvBL1 or RuvBL2 have phenotypes typically observed in embryos with defects in the motile cilia, including a curved body shape and kidney cysts. Although the levels of transcription in many components that build the dynein arms were unchanged [15,48], the transmission electron microscopy (TEM) analysis showed that, in both mutants, cilia had a reduced number of ODAs and IDAs [15]. Immunofluorescence analysis of mouse ependymal and oviduct epithelial multiciliated cells, as well as studies of Kupffer's vesicle and pronephric ciliated cells in zebrafish, showed that RuvBL1 was present in the cytoplasm [15,49] and in the nucleus [49]. Contradictory to these data, using a non-commercial antibody, it was shown that in Chlamydomonas RuvBL1 was also present in flagella [50].

In transgenic RuvBL1 $1^{\text {frt-fl }}$ mice disruption of ciliary integrity was observed, causing renal disease and hydrocephalus [49]. In mice, loss-of-function mutations of RuvBL1 is lethal at an early embryonic stage, but deletion of the RuvBL1 only in premeiotic male germ cells causes male infertility [15]. A reduction and/or lack of DNAH9 (Dynein heavy chain), DNAI2 (Dynein intermediate chain), and DNALI1 (light intermediate chain-1) in sperm flagella and cilia of multiciliated cells suggest the possible involvement of RuvBL1 in dynein arms' preassembly or stability [15,49]. Interestingly, the co-immunoprecipitation analyses (from testis of mutant mice) revealed that when RubBL1 was mutated, both RuvBL1-RuvBL2-Hsp90 and DNAI1-DNAI2 complexes failed to form. These data can point to the role of RuvBL1 and RuvBL2 as co-chaperones in the folding and stabilization of DNAI1-DNAI2 complex (Table 2) [15]. To date, mutations in RuvBL1 or RuvBL2 have not been associated with PCD in humans, likely because these proteins function as co-chaperones for the assembly of diverse protein complexes and their mutations would cause death during early development, as was observed in mice [15]. 
Table 2. Summary of the experimental data showing which component of ODA and/or IDA are missing in cilia assembled by the cells with mutated co-chaperone or DNAAFs.

\begin{tabular}{|c|c|c|c|c|c|c|c|c|}
\hline & \multicolumn{2}{|c|}{ Chlamydomonas } & \multicolumn{2}{|c|}{ Danio rerio } & \multicolumn{2}{|c|}{ Mouse } & \multicolumn{2}{|c|}{ Humans } \\
\hline & ODA & IDA & ODA & IDA & ODA & IDA & ODA & IDA \\
\hline RuvBL1-RuvBL2 & & & & & $\begin{array}{c}\text { DNAH9, } \\
\text { DNAI2 }[15,49]\end{array}$ & $\begin{array}{c}\text { DNALI1 } \\
\text { [49] }\end{array}$ & & \\
\hline PIH1D1/MOT48 & & IDA b, c, [51] & DNAI1 [52] & IDAc [52] & & & & \\
\hline PIH1D2 & & & $\begin{array}{c}\text { DNAH8, } \\
\text { DNAI1 [52] }\end{array}$ & IDA b,c,e [52] & & & & \\
\hline WDR92 & $\begin{array}{c}\alpha \mathrm{HC}, \beta H C, \\
\text { YHC, } \\
\text { IC/LC } \\
{[53,54]}\end{array}$ & $\begin{array}{l}\text { DHC5, DHC8, } \\
\text { DHC9 [53] }\end{array}$ & $\begin{array}{c}\text { DNAH17, } \\
\text { DNAH8 } \\
\text { DNAI1-DNAI2, } \\
\text { DNAL4 [55] }\end{array}$ & $\begin{array}{c}\text { DNAH12, } \\
\text { DNAH10, } \\
\text { Centrin [55] }\end{array}$ & & & & \\
\hline SPAG1 & & & & & & & $\begin{array}{c}\text { DNAH5, DNAI1 } \\
{[28]}\end{array}$ & $\begin{array}{c}\text { DNALI1 } \\
\text { [28] }\end{array}$ \\
\hline DNAAF1/ODA7 & $\begin{array}{c}\mathrm{HC} \alpha, \text { IC70, IC78 } \\
{[13]}\end{array}$ & ID1 [13] & & & & & $\begin{array}{c}\text { DNAH5, DNAH9, } \\
\text { DNAI2 } \\
{[56,57]}\end{array}$ & DNALI1 $[56,57]$ \\
\hline DNAAF2 & $\begin{array}{c}\mathrm{HC} \alpha, \mathrm{HC} \beta \\
\mathrm{HCY} \\
{[16]}\end{array}$ & HC9 [16] & $\begin{array}{c}\text { DNAH8 DNAI1 } \\
{[52]}\end{array}$ & IDA b,c,e [52] & & & $\begin{array}{l}\text { DNAH5, DNAH9, } \\
\text { DNAI2 [16] }\end{array}$ & DNALI1 [16] \\
\hline DNAAF4 & & & & & $\begin{array}{l}\text { DNAH5, } \\
\text { DNAH9, } \\
\text { DNAI2 [30] }\end{array}$ & $\begin{array}{c}\text { DNALI1 } \\
{[30]}\end{array}$ & DNAH5 [30] & DNALI1 [30] \\
\hline DNAAF5 & & $\begin{array}{c}\mathrm{DIC} 2 / \mathrm{IC} 78 \\
{[32]}\end{array}$ & DNALI1 [31] & & & & DNAH5 [31] & DNALI1 [31] \\
\hline DNAAF6 & & & $\begin{array}{c}\text { DNAH8, } \\
\text { DNAI1 [53] }\end{array}$ & IDA c,d,g [52] & $\begin{array}{c}\text { DNAH5, } \\
\text { DNAI1, [34] }\end{array}$ & $\begin{array}{c}\text { DNALI1 } \\
\text { [34] }\end{array}$ & & \\
\hline DNAAF7 & & & & & $\begin{array}{c}\text { DNAH5, } \\
\text { DNAI2 [58] }\end{array}$ & TCTEX1D1 [58] & DNAH5 [35] & DNAL1 [35] \\
\hline LRRC6 & & & & & & & $\begin{array}{c}\text { DNAI1, DNAI2 } \\
{[37,38]}\end{array}$ & $\begin{array}{c}\text { DNAH7 } \\
\text { DNALI2 } \\
{[37,38]}\end{array}$ \\
\hline
\end{tabular}


Similarly, the analyses of Chlamydomonas and Danio rerio mutants suggested the involvement of PIH1D1 in dynein arms' assembly. Comparative studies of Danio rerio WT and pih1d1_null mutant revealed the abnormal motility of sperm flagella and Kupffer's vesicle cilia caused by the loss of outer and inner dynein arms. As confirmed by cryo-electron tomography analyses of cilia assembled by the Danio rerio mutant, PIH1D1 is necessary for the proper assembly of ODA (DNAI1 was not detected using immunofluorescence) and IDA c (Table 2) [52]. Accordingly, the Chlamadymonas ida10 mutants lacking MOT48, an ortholog of PIH1D1 [51], are either immotile or move significantly slower. The phenotypic changes were caused by the reduction in the number of IDAs $b$ and $c$, while IDAs f/I1 and $g$ were almost unaffected or only slightly reduced, similarly to ODAs [51]. The biochemical studies revealed that MOT48 interacts with RuvBL1, RuvBL2, RPAP3, and DNAAF4/DYX1C (Table 1) [53].

The WD repeat-containing protein 92 (WDR92) has been reported to associate with the R2TP complex (Figure 2) [59,60]. Recently, the participation of WDR92 and the canonical R2TP complex in the pre-assembly of dynein arms has been revealed [53-55,61]. The comparative genomic studies demonstrate that WDR92 genes are highly conserved in organisms with motile cilia [54,61]. The initial evidence that WDR92 associates with ciliary motility proteins was provided by studies in planarian Schmidtea mediterranea. It was shown that animals deficient in WDR92 still assembled in cilia of normal length, and in similar numbers to WT, but ciliary beat frequency was reduced. TEM analysis revealed that many cilia had defects in their architecture, including partial loss of the outer dynein arms [61]. WDR92 is also required for the assembly of ODAs and IDAs in Drosophila and Chlamydomonas (Table 2). Drosophila melanogaster has only two cell types bearing motile cilia: the sperm flagellum and the ciliated proprioceptive chordotonal sensory neurons [55]. Mutations in WDR92 result in male infertility and auditory deficiency. Cross-sections of the cilia of WDR92 Drosophila mutants showed an absence of ODAs and IDAs [55]. The Chlamydomonas WRD92 mutant assembles very short cilia lacking inner and outer dynein arms. Moreover, the level of dynein arm heavy chains in the cytoplasm is low [53,54]. Data obtained during the comparative mass spectrometry analysis of wild type and Drosophila mutant sperm flagella [55], and analyses of the WDR92 Chlamydomonas phenotype [54], suggest that WDR92 is required for the stabilization of the folded dynein heavy chains (Table 2). Interestingly, in Drosophila WDR92 mutants the level of DNAAF2/KTU/PF13 and DNAAF4 was elevated, suggesting that DNAAF2 and DNAAF4 could form an R2TP-like co-chaperone complex for an early HC assembly step [55]. Moreover, in S2 Drosophila cells, WDR92 co-immunoprecipitates with several proteins, including RPAP3, PIH1D1, RuvBL1, RuvBL2, DNAAF1/LRRC50/ODA7 and SPAG1 (Table 1) [55]. Similarly, immunoprecipitation followed by mass spectrometry revealed that in Chlamydomonas, WDR92 directly or indirectly interacts with inner dynein arm heavy chains, RuvBL1, and multiple DNAAFs, including RPAP3, MOT48 (Chlamydomonas orthologue of PIH1D1), ODA7 (Chlamydomonas orthologue of DNAAF1), and DNAF4 (Table 1) [53]. In mammalian and Drosophila cells, WDR92 binds to RPAP3, potentially through the RPAP3 C-terminal domain [55,62].

\subsection{Composition of R2SP Complex and Function in Dynein Arm Preassembly}

The R2SP (RuvBL1-ㅍuvBL2-SPAG1-PIH1D2) complex is related to the R2TP complex, with RPAP3 and PIH1D1 adaptors being replaced by SPAG1 (sperm associated antigen 1) and PIH1D2, respectively [63] (Figure 2). SPAG1 contains three TPR domains in its N-terminal end and RPAP3-C-ter domain at its C-terminus (Figure 2). Moreover, SPAG1 also interacts with Hsp90 and Hsp70 [63].

Data from various organisms indicate that SPAG1 is involved in the pre-assembly of dynein arms $[28,63,64]$. Knockdown of SPAG1 in Danio rerio caused a phenotype typically observed when motile cilia are dysfunctional (dorsal body axis curvature, and hydrocephalus [28]). Sperm cells of the Drosophila mutant depleted of CG18472, an orthologue of SPAG1, were immotile. Moreover, the TEM analysis of the chordotonal sensory neuron cilium revealed a loss of dynein arms (ODAs, IDAs) (Table 2) [55]. In humans, mutations in SPAG1 cause primary ciliary dyskinesia (CILD28) [28].

SPAG1, like other proteins with TPR domains, (Table 1) mediates the delivery of clients from Hsp70 to Hsp90, thanks to simultaneous anchoring of the chaperones via EEVD residues within Hsp70 and 
Hsp90 C-terminal end to the designed TPR domains of SPAG1 [64]. SPAG1, besides RuvBL1, RuvBL2, and PIH1D2, interacts (possibly indirectly) with DNAAF5/HEATR2 (HEAT Repeat-Containing) and DNAAF2 (Table 1), and co-localizes with them in DynAPs [27,65]. Recent studies on ciliogenesis in human primary airway epithelial cells have shown that DNAAF5, SPAG1, and DNAAF2 undergo transcription during the early stages of airway epithelial cell differentiation. The analyses of the epithelial respiratory cells obtained from PCD patients during biopsies have shown that mutations in DNAAF5 do not disrupt direct interaction with SPAG1, but cause the accumulation of large DNAAF5-SPAG1-DNAAF2 aggregates and degradation of all three proteins [65].

On the other hand, preassembly genes such as DNAAF1, DNAAF3, DNAAF4, LRRC6, DNAAF6/PIH1D3/TWISTER/TWI, and DNAAF7/ZMYND10, were expressed at a later stage of cell differentiation, similar to dynein DNAI1 [65]. Based on these data, it can be assumed that R2SP is involved in the early phase of the formation of dynein arms when SPAG1 binds to DNAAF2. However, the R2SP complex can interact with the late preassembly proteins, e.g., DNAAF4 and DNAAF6 [30,33] and WDR92, as was shown in human cells [66] and later confirmed in Drosophila [55]. It is likely that WDR92 contributes to cooperation between R2SP and R2TP [55]. Biochemical analyses of Drosophila testis showed that SPAG1 binds to Dhc98D (DNAH10), a heavy chain inner arm dynein also associated with WDR92 [55]. In the presence of overexpressed RuvBL1 and RuvBL2, the association of SPAG1 with WDR92 was enhanced in S2 Drosophila cells. Such observations favor the hypothesis that WDR92-SPAG1 may form part of a conserved co-chaperone complex [55].

The PIH1D2 (Figure 2) protein plays an important role in the formation of the R2SP complex by facilitating the interaction between SPAG1 and RuvBL1-RuvBL2 (Table 1) [63]. Moreover, recent data indicate that PIH1D2 is also involved in dynein arms' assembly. Cilia in Kupffer's vesicle and sperm cell flagella of Danio rerio pih1d2-null mutant are either immotile or move irregularly. Accordingly, cryo-ET and biochemical analyses revealed that the PIH1D2 protein is required for the assembly of ODA and IDA b, c, and e subunits (Table 2) [52].

\subsection{DNAAFs and Their Function in Dynein Arm Assembly}

As mentioned above, the identification of the causative mutations in the individuals affected by PCD, with characteristic loss of dynein arms without changes in the genes encoding dynein arm components, led to the discovery of a number of cytoplasmic proteins called DNAAFs that participate in dynein arms' preassembly.

Although the ciliary ultrastructural outcome of the mutations in DNAAFs is well known, the molecular mechanisms behind their activity, and data concerning DNAAFs' partners and interactions between DNAAFs and chaperones/co-chaperones, are fragmentary. Below, we briefly summarize the current state of knowledge.

Proteins that function as DNAAFs contain different domains (e.g., TPR, PIH1, CS, LRRC) (Figure 2) that enable interactions with other proteins and complex formation. The genomes of the vertebrates encode four proteins with a PIH1 domain at the N-terminal end and CS domain in the C-terminal fragment: PIH1D1, PIH1D2, both described above, which form the canonical R2TP and R2SP complexes, respectively [19], and dynein assembly factors, DNAAF2 and DNAAF6 [15,63,67].

DNAAF2/KTU/PF13 was the first protein identified as a DNAAF (Figure 2, Table 1) [16]. The presence of PIH1 and CS domains suggest that DNAAF2 could potentially form a complex with RuvBL1 and RuvBL2. However, such interactions in vivo were not confirmed at least in Chlamydomonas [53]. On the other hand, DNAAF2 interacts with DNAAF4 [30,53], which can facilitate complex formation between DNAAF2-DNAAF4 and Hsp90 [34,63] and Hsp70 [16]. DNAAF2 is required for ODA and IDA heavy chain stability, possibly by assisting the assembly of the heavy chains with other subunits (Table 2). The flagella in Chlamydomonas mutants lacking DNAAF2 are completely paralyzed [16]. Studies of the Danio rerio mutant lacking DNAAF2 revealed normal sperm motility, but the motility of cilia in Kupffer's vesicle was irregular, or exhibited a slower rotation, caused by the loss of dynein arm ODA, and IDA b, c, and e subtypes (Table 2) [52]. 
Genetic, immunocytochemical and TEM studies performed on fish medaka (Oryzias latipes) and human respiratory cells have shown that, in the absence or mutation of DNAAF2, cilia are assembled normally, but both the outer and inner dynein arms are missing [16]. In humans, mutations in the gene encoding DNAAF2 cause PCD (CILD10) [16].

With the exception of Olcese and co-workers [34], in several other studies it was suggested that the PIH1 domain is present in the N-terminal fragment of DNAAF6/PIH1D3 [33,52,63,67] (Figure 2). DNAAF6 also contains a CS domain at its C-terminus and, as confirmed by co-immunoprecipitation, analysis can form a complex (interacting directly or indirectly) with Hsp70 and/or Hsp90 [34,67]. In humans, mutations in the X-linked DNAAF6/PIH1D3 causes PCD (CILD36), due to the defects in both the outer and inner dynein arms [33,34]. In contrast to the human genome encoding a single PIH1D3 gene, two Pih1d3 genes are present in mice genome, one located on chromosomes 1 (Pih1d3a, 4930521A18Rik) and one on chromosome X (Pih1d3b, E230019M04Rik). Pih1d3a and Pih1d3b proteins are $91 \%$ identical, with differences mainly within the unstructured $\mathrm{N}$-terminal end. Pih1d3a is present exclusively in the testis. Mice with knocked out Pih1d3a produce sperm cells with immotile flagella due to dynein arm defects, while motile cilia in other organs are unaffected. Immunochemical analysis revealed that the levels of DNAH9/HC $\beta$, DNAIC1/IC1, and DNAIC2/IC2 (components of ODAs), and DNAH7/HC (a component of IDAs) were reduced in knock-out sperm compared with those of WT mice [67]. The X-linked Pih1d3b is expressed in mice lung, brain, and oviduct. The Pih1d3b cannot rescue the sperm flagella defect arising from the loss of Pih1d3a. In Danio rerio, mutants lacking DNAAF6 sperm flagella and Kupffer's vesicle cilia are immotile. Cryo-electron tomography showed that the mutated axoneme lacks ODA, IDA c, g, and d (Table 2) [52]. Interestingly, mutations in TWI1, a Chlamydomonas ortholog of DNAAF6, do not affect flagella motility and cells' swimming, suggesting that TWI1 is most likely not involved in dynein arm assembly in this green algae [53]. On the other hand, like other proteins involved in the dynein arms' assembly, TWI1 is strongly upregulated upon deflagellation [47].

Some DNAAFs, in addition to a CS domain, also have TRP domains that enable direct binding to Hsp70 and/or Hsp90. DNAAF4/DYX1C (Figure 2) has three TRP domains and it can form a DNAAF2DNAAF4-Hsp90 co-chaperone complex (Table 1), and, thus, can link the assembly of axonemal dynein to Hsp90 [30,53,68]. Tarkar and co-workers [30] showed that DNAAF4 deficiency in humans, mice, and zebrafish results in defects in the motile cilia, caused by deficient dynein arm transport or assembly. The deletion of DNAAF4 in mice [30] and mutations in humans [30] cause symptoms characteristic of PCD (chronic airway disease, laterality defects, and male infertility) (CILD25). Similar phenotypic changes typical for motile ciliary dysfunction (laterality and ciliary motility defects) were observed after a reduction in the expression of DNAAF4 in zebrafish [30]. Ultrastructural and immunofluorescence analysis of motile cilia assembled by the respiratory cells in mice and humans revealed disturbed ODA and IDA organization. The components of ODAs (DNAH5, DNAH9, and DNAI2) and IDAs (DNALI1) were absent or significantly reduced (Table 2) [30] in these cilia.

Both RuvBL1 and RuvBL2 can also interact with DNAAF1/LRRC50/ODA7 (Leucine-Rich Repeat-Containing 50) (Figure 2, Table 1) [56]. Mutations of DNAAF1/ODA7 in Chlamydomonas reduce flagella beat frequency and a block outer dynein arm assembly $[13,68]$. The biochemical and immunofluorescence analyses indicate that DNAAF1/ODA7 and its orthologue in Trypanosoma brucei similar to other a DNAAFs, is localized in the cytoplasm [17,29]. DNAAF1 over-expressed in ciliated hTERT-RPE1 cells co-localized with IFT88 at the base of the primary cilium and RuvBL1 knockdown caused disruption of this co-localization [56]. In humans, cilia of the respiratory cells obtained from the patients carrying a DNAAF1 mutation (CILD13), lacked ODAs and IDAs subunits (DNAH5, DNAH9, DNAI2 and DNALI1) (Table 2) [29,57]. Interestingly, in humans the mutation in DNAAF1 was also associated with neural tube defects (DNAAF1 seems to be essential for the final step of neural tube closure) [69]. Similar to humans, mutations of DNAAF1 in mice and zebrafish cause changes typical of PCD in these species [56]. The biochemical analysis revealed that several heat shock proteins, including Hsp90, were more strongly associated with the mutanted DNAAF1 protein than the wild-type protein, 
which may be evidence of a possible instability of the mutated protein. While both RuvBL1 and RuvBL2 proteins interacted with wild-type DNAAF1, interaction with RuvBL1 was reduced in the case of the DNAAF1 mutant [56].

LRRC6/Seahorse (Leucine-Rich Repeat-Containing 6) (Figure 2) is another DNAAFs whose defects cause primary ciliary dyskinesia (CILD19) [37-39]. LRRC6, containing several LRR repeats is another protein expressed specifically in cells with motile cilia, including the nodal, tracheal, and sperm cells in mice [39]. LRRC6, in addition to six LRR repeats at the N-terminus, also contains a CS domain at the C-terminus [48]. The CS domain is likely essential for the direct interaction between LRRC6 and RuvBL2 [35,37,48] or DNAAF7 [35] (Table 1). In mutant mice and individuals affected with PCD lacking LRRC6 the length of cilia was normal, but nodal and typical motile cilia were immotile due to the loss of IDAs and ODAs [37-39] (Table 2). Probably, the lack of IDAs and ODAs in the axoneme of the mutant lacking LRRC6 was caused by defective transport of the dynein arm to the cilia [39].

DNAAF7/ZMYD10 (zinc finger MYND-type-containing 10) (Figure 2) is a cytoplasmic protein possessing Mynd-type zinc finger domain (myeloid, nervy, and DEAF-1) at its C-terminus that engages in protein-protein interaction [70]. DNA $\overline{\mathrm{AF}} 7$ is highly expressed in cells assembling motile cilia, compared with nonciliated cells [36,71]. Previous studies have established a strong genetic link between loss or mutation of DNAAF7 and a combined outer and inner dynein arms defect in model organisms (fly, medaka, Xenopus, mouse) and humans (PCD, CILD22) [35,36,72,73]. DNAAF7 interacts with RuvBL2 [58] and LRRC6 [35,58,74]. It was shown that the C-terminal fragment of DNAAF7 and the CS domain of LRRC6 were necessary for this interaction [35]. DNAAF7 also forms complexes with C21ORF59 and DNAAF4, IDAs' dynein light chain, and components of ODAs such as TCTEX1D1 (Tctex1 domain-containing D1) and DNAI1 (Table 2) [58]. Recently, Mali and co-workers [74] revealed that, in murine cells, DNAAF7 can form a novel chaperone complex comprising DNAAF7, FKBP8, and Hsp90, which can take part in the maturation of dynein heavy chains.

In addition to the DNAAFs proteins described above, several other DNAAF proteins were identified: DNAAF3/C19orf51 (CILD2) [17,75], and CFAP300/C11orf70 (CILD38) [76-78], CFAP298/ C21orf59/FBB18/KURLY (CILD26) [79]. However, until now their partner proteins and potential interactions with co-chaperones to form R2TP-like complexes were not described.

\section{Conclusions and Perspective}

The mechanism responsible for the cytoplasmic preassembly of the dynein arms components, the loading of these complexes onto the IFT system and their delivery and docking to the axoneme is still only fragmentarily understood. Although, in recent years, numerous proteins involved in the assembly of ODA and IDA have been identified, the still enigmatic interactions between chaperones, co-chaperones, DNAAFs and dynein arms subunits in this multi-step and complex processes are not clear. Moreover, to some extent, distinct mechanisms involved in the assembly of individual IDA and ODA components further impede understanding of these processes. In addition, it should be emphasized that impairment of dynein arms pre-assembly is not due to abnormalities in the level of transcription and/or translation, but the lower stability of individual ODA or IDA proteins resulting from the lack or dysfunction of R2TP, and/or R2SP and/or R2TP-like complexes. Also, the incomplete understanding of the mechanism of dynein arm folding and the role of co-chaperone complexes is partly due to methodological limitations. In the overwhelming majority of studies, the lack or lower level of individual dynein arms is determined by immunofluorescence labelling using antibodies that recognize individual proteins. Unfortunately, the availability of antibodies is limited to only few proteins, and more precise methods based on cryo-electron microscopy are only now being introduced. However, a better understanding of the mechanism of dynein arm preassembly is necessary and urgent. In humans, an improperly carried out preassembly of dynein arms results in primary ciliary dyskinesia (MIM:244400). PCD is a rare disease, affecting 1 in 10,000-15,000 live births [80,81]. The hallmark phenotype of PCD includes chronic sinusitis, recurring respiratory tract infections, infertility, situs inversus, and, rarely, hydrocephalus [82-84]. Moreover, around 50\% of individuals affected with PCD 
suffer from disorders of laterality (situs inversus), also known as Kartagener syndrome, which is due to the failure of nodal cilia function and is often associated with cardiac development disorders $[56,85]$. A proper diagnosis of PCD is still challenging, especially when patients manifest non-specific signs and symptoms. This begs the question of how to help solve this problem. The identification of new PCD genes whose mutations may cause phenotypic changes significantly increases patients' chances for proper diagnosis. The implementation of genetic and molecular diagnosis of PCD is a necessity, regardless of whether it is used as a confirmation of clinical diagnosis or when PCD is suspected. Unfortunately, hopes of the implementation of PCD gene therapy, which could help patients suffering from this disease, are still rather distant taking into account the current stage of knowledge.

Author Contributions: Both authors searched and organized data concerning interactions between DNAAFs and chaperone Hsp90 co-chaperones, R2TP and R2TP-like complexes. H.F. wrote the initial version of the manuscript. Both authors worked on the final version of the manuscript.

Funding: This project was supported by the Nencki Institute of Experimental Biology PAS and grant National Science Centre 2017/25/B/NZ3/01609.

Acknowledgments: We are very grateful to Dorota Włoga and Wieslawa Lesniak for their help in the preparation of the manuscript.

Conflicts of Interest: The authors declare no conflict of interest.

\section{References}

1. Pitnick, S.; Markow, T.A.; Spicer, G.S. Delayed male maturity is a cost of producing large sperm in Drosophila. Proc. Natl. Acad. Sci. USA 1995, 92, 10614-10618. [CrossRef]

2. Fliegauf, M.; Benzing, T.; Omran, H. When cilia go bad: Cilia defects and ciliopathies. Nat. Rev. Mol. Cell Biol. 2007, 8, 880-893. [CrossRef]

3. Nonaka, S.; Shiratori, H.; Saijoh, Y.; Hamada, H. Determination of left-right patterning of the mouse embryo by artificial nodal flow. Nature 2002, 418, 96-99. [CrossRef]

4. Ishikawa, H.; Marshall, W.F. Ciliogenesis: Building the cell's antenna. Nat. Rev. Mol. Cell Biol. 2011, 12, 222-234. [CrossRef] [PubMed]

5. Hirokawa, N.; Tanaka, Y.; Okada, Y. Left-right determination: Involvement of molecular motor KIF3, cilia, and nodal flow. Cold Spring Harb. Perspect. Biol. 2009, 1, a000802. [CrossRef] [PubMed]

6. Nicastro, D.; Schwartz, C.; Pierson, J.; Gaudette, R.; Porter, M.E.; Mcintosh, J.R. The molecular architecture of axonemes revealed by cryoelectron tomography. Science 2006, 313, 944-948. [CrossRef] [PubMed]

7. Urbanska, P.; Joachimiak, E.; Bazan, R.; Fabczak, H.; Włoga, D. Motile cilia-From ultrastructure to function. Kosmos 2018, 67, 195-205.

8. Kamiya, R. Functional diversity of axonemal dyneins as studied in Chlamydomonas mutants. Int. Rev. Cytol. 2002, 219, 115-155. [CrossRef]

9. Kollmar, M. Fine-Tuning Motile Cilia and Flagella: Evolution of the dynein motor proteins from plants to humans at high resolution. Mol. Biol. Evol. 2016, 33, 3249-3267. [CrossRef]

10. Kamiya, R.; Yagi, T. Functional diversity of axonemal dyneins as assessed by in vitro and in vivo motility assays of Chlamydomonas mutants. Zoolog. Sci. 2014, 31, 633-644. [CrossRef]

11. Ishikawa, T. Axoneme Structure from Motile Cilia. Cold Spring Harb. Perspect. Biol. 2017, 9, a028076. [CrossRef] [PubMed]

12. Fok, A.K.; Wang, H.; Katayama, A.; Aihara, M.S.; Allen, R.D. 22S axonemal dynein is preassembled and functional prior to being transported to and attached on the axonemes. Cell Motil. Cytoskelet. 1994, 29, 215-224. [CrossRef] [PubMed]

13. Fowkes, M.E.; Mitchell, D.R. The role of preassembled cytoplasmic complexes in assembly of flagellar dynein subunits. Mol. Biol. Cell 1998, 9, 2337-2347. [CrossRef] [PubMed]

14. Ahmed, N.T.; Gao, C.; Lucker, B.F.; Cole, D.G.; Mitchell, D.R. ODA16 aids axonemal outer row dynein assembly through an interaction with the intraflagellar transport machinery. J Cell Biol. 2008, 183, 313-322. [CrossRef] [PubMed]

15. Li, Y.; Zhao, L.; Yuan, S.; Zhang, J.; Sun, Z. Axonemal dynein assembly requires the R2TP complex component Pontin. Development 2017, 144, 4684-4693. [CrossRef] 
16. Omran, H.; Kobayashi, D.; Olbrich, H.; Tsukahara, T.; Loges, N.T.; Hagiwara, H.; Zhang, Q.; Leblond, G.; O'Toole, E.; Hara, C.; et al. Ktu/PF13 is required for cytoplasmic pre-assembly of axonemal dyneins. Nature 2008, 456, 611-616. [CrossRef]

17. Mitchison, H.M.; Schmidts, M.; Loges, N.T.; Freshour, J.; Dritsoula, A.; Hirst, R.A.; O'Callaghan, C.; Blau, H.; Al Dabbagh, M.; Olbrich, H.; et al. Mutations in axonemal dynein assembly factor DNAAF3 cause primary ciliary dyskinesia. Nat. Genet. 2012, 44, 381-389. [CrossRef]

18. Desai, P.B.; Dean, A.B.; Mitchell, D.R. Cytoplasmic preassembly and trafficking of axonemal dyneins. In The Biology of Dynein Motors; King, S., Ed.; Elsevier Inc.: Cambridge, MA, USA, 2018; pp. 141-161. [CrossRef]

19. Kakihara, Y.; Houry, W.A. The R2TP complex: Discovery and functions. Biochim. Biophys. Acta 2012, 1823, 101-107. [CrossRef]

20. Schopf, F.H.; Biebl, M.M.; Buchner, J. The HSP90 chaperone machinery. Nat. Rev. Mol. Cell Biol. 2017, 18, 345-360. [CrossRef]

21. Hartl, F.U.; Bracher, A.; Hayer Hartl, M. Molecular chaperones in protein folding and proteostasis. Nature 2011, 475, 324-332. [CrossRef]

22. Li, J.; Buchner, J. Structure, function and regulation of the Hsp90 machinery. Biomed. J. 2013, 36, $106-117$. [CrossRef] [PubMed]

23. Lynham, J.; Houry, W.A. The Multiple Functions of the PAQosome: An R2TP- and URI1 Prefoldin-Based Chaperone Complex. Adv. Exp. Med. Biol. 2018, 1106, 37-72. [CrossRef] [PubMed]

24. Zhao, R.; Davey, M.; Hsu, Y.C.; Kaplanek, P.; Tong, A.; Parsons, A.B.; Krogan, N.; Cagney, G.; Mai, D.; Greenblatt, J.; et al. Navigating the chaperone network: An integrative map of physical and genetic interactions mediated by the Hsp90 chaperone. Cell 2005, 120, 715-727. [CrossRef] [PubMed]

25. Muñoz-Hernández, H.; Pal, M.; Rodríguez, C.F.; Fernandez-Leiro, R.; Prodromou, C.; Pearl, L.H.; Llorca, O. Structural mechanism for regulation of the AAA-ATPases RUVBL1-RUVBL2 in the R2TP co-chaperone revealed by cryo-EM. Sci. Adv. 2019, 5, eaaw1616. [CrossRef] [PubMed]

26. Muñoz-Hernández, H.; Pal, M.; Rodríguez, C.F.; Prodromou, C.; Pearl, L.H.; Llorca, O. Advances on the structure of the R2TP/Prefoldin-like complex. Adv. Exp. Med. Biol. 2018, 1106, 73-83. [CrossRef]

27. Huizar, R.L.; Lee, C.; Boulgakov, A.A.; Horani, A.; Tu, F.; Marcotte, E.M.; Brody, S.L.; Wallingford, J.B. A liquid-like organelle at the root of motile ciliopathy. eLife 2018, 7, e38497. [CrossRef]

28. Knowles, M.R.; Ostrowski, L.E.; Loges, N.T.; Hurd, T.; Leigh, M.W.; Huang, L.; Wolf, W.E.; Carson, J.L.; Hazucha, M.J.; Yin, W.; et al. Mutations in SPAG1 cause primary ciliary dyskinesia associated with defective outer and inner dynein arms. Am. J. Hum. Genet. 2013, 93, 711-720. [CrossRef]

29. Duquesnoy, P.; Escudier, E.; Vincensini, L.; Freshour, J.; Bridoux, A.M.; Coste, A.; Deschildre, A.; de Blic, J.; Legendre, M.; Montantin, G.; et al. Loss-of-function mutations in the human ortholog of Chlamydomonas reinhardtii ODA7 disrupt dynein arm assembly and cause primary ciliary dyskinesia. Am. J. Hum. Genet. 2009, 85, 890-896. [CrossRef]

30. Tarkar, A.; Loges, N.T.; Slagle, C.E.; Francis, R.; Dougherty, G.W.; Tamayo, J.V.; Shook, B.; Cantino, M.; Schwartz, D.; Jahnke, C.; et al. DYX1C1 is required for axonemal dynein assembly and ciliary motility. Nat. Genet. 2013, 45, 995-1003. [CrossRef]

31. Horani, A.; Druley, T.E.; Zariwala, M.A.; Patel, A.C.; Levinson, B.T.; Van Arendonk, L.G.; Thornton, K.C.; Giacalone, J.C.; Albee, A.J.; Wilson, K.S.; et al. Whole-exome capture and sequencing identifies HEATR2mutation as a cause of primary ciliary dyskinesia. Am. J. Hum. Genet. 2012, 91, 685-693. [CrossRef]

32. Diggle, C.P.; Moore, D.J.; Mali, G.; zur Lage, P.; Ait-Lounis, A.; Schmidts, M.; Shoemark, A.; Garcia Munoz, A.; Halachev, M.R.; Gautier, P.; et al. HEATR2 plays a conserved role in assembly of the ciliary motile apparatus. PLoS Genet. 2014, 10, e1004577. [CrossRef] [PubMed]

33. Paff, T.; Loges, N.T.; Aprea, I.; Wu, K.; Bakey, Z.; Haarman, E.G.; Daniels, J.M.A.; Sistermans, E.A.; Bogunovic, N.; Dougherty, G.W.; et al. Mutations in PIH1D3 cause X-linked primary ciliary dyskinesia with outer and inner dynein arm defects. Am. J. Hum. Genet. 2017, 100, 160-168. [CrossRef] [PubMed]

34. Olcese, C.; Patel, M.P.; Shoemark, A.; Kiviluoto, S.; Legendre, M.; Williams, H.J.; Vaughan, C.K.; Hayward, J.; Goldenberg, A.; Emes, R.D.; et al. X-linked primary ciliary dyskinesia due to mutations in the cytoplasmic axonemal dynein assembly factor PIH1D3. Nat. Commun. 2017, 8, 14279. [CrossRef] [PubMed] 
35. Zariwala, M.A.; Gee, H.Y.; Kurkowiak, M.; Al-Mutairi, D.A.; Leigh, M.W.; Hurd, T.W.; Hjeij, R.; Dell, S.D.; Chaki, M.; Dougherty, G.W.; et al. ZMYND10 is mutated in primary ciliary dyskinesia and interacts with LRRC6. Am. J. Hum. Genet. 2013, 93, 336-345. [CrossRef]

36. Moore, D.J.; Onoufriadis, A.; Shoemark, A.; Simpson, M.A.; zur Lage, P.I.; de Castro, S.C.; Bartoloni, L.; Gallone, G.; Petridi, S.; Woollard, W.J.; et al. Mutations in ZMYND10, a gene essential for proper axonemal assembly of inner and outer dynein arms in humans and flies, cause primary ciliary dyskinesia. Am. J. Hum. Genet. 2013, 93, 346-356. [CrossRef]

37. Kott, E.; Duquesnoy, P.; Copin, B.; Legendre, M.; Dastot-Le Moal, F.; Montantin, G.; Jeanson, L.; Tamalet, A.; Papon, J.F.; Siffroi, J.P.; et al. Loss-of-function mutations in 1rrc6, a gene essential for proper axonemal assembly of inner and outer dynein arms, cause primary ciliary dyskinesia. Am. J. Hum. Genet. 2012, 91, 958-964. [CrossRef]

38. Horani, A.; Ferkol, T.W.; Shoseyov, D.; Wasserman, M.G.; Oren, Y.S.; Kerem, B.; Amirav, I.; Cohen-Cymberknoh, M.; Dutcher, S.K.; Brody, S.L.; et al. LRRC6 mutation causes primary ciliary dyskinesia with dynein arm defects. PLoS ONE 2013, 8, e59436. [CrossRef]

39. Inaba, Y.; Shinohara, K.; Botilde, Y.; Nabeshima, R.; Takaoka, K.; Ajima, R.; Lamri, L.; Takeda, H.; Saga, Y.; Nakamura, T.; et al. Transport of the outer dynein arm complex to cilia requires a cytoplasmic protein Lrrc6. Genes Cells 2016, 21, 728-739. [CrossRef]

40. Pal, M.; Morgan, M.; Phelps, S.E.; Roe, S.M.; Parry-Morris, S.; Downs, J.A.; Polier, S.; Pearl, L.H.; Prodromou, C. Structural basis for phosphorylation-dependent recruitment of Tel2 to Hsp90 by Pih1. Structure 2014, 22, 805-818. [CrossRef]

41. Horejsi, Z.; Takai, H.; Adelman, C.A.; Collis, S.J.; Flynn, H.; Maslen, S.; Skehel, J.M.; de Lange, T.; Boulton, S.J. CK2 phospho-dependent binding of R2TP complex to TEL2 is essential for mTOR and SMG1 stability. Mol. Cell. 2010, 39, 839-850. [CrossRef]

42. Horejsi, Z.; Stach, L.; Flower, T.G.; Joshi, D.; Flynn, H.; Skehel, J.M.; O’Reilly, N.J.; Ogrodowicz, R.W.; Smerdon, S.J.; Boulton, S.J. Phosphorylation-dependent PIH1D1 interactions define substrate specificity of the R2TP cochaperone complex. Cell Rep. 2014, 7, 19-26. [CrossRef] [PubMed]

43. Ali, M.M.; Roe, S.M.; Vaughan, C.K.; Meyer, P.; Panaretou, B.; Piper, P.W.; Prodromou, C.; Pearl, L.H. Crystal structure of an Hsp90-nucleotide-p23/Sba1 closed chaperone complex. Nature 2006, 440, 1013-1017. [CrossRef] [PubMed]

44. Benbahouche, N.H.; Iliopoulos, I.; Török, I.; Marhold, J.; Henri, J.; Kajava, A.V.; Farkaš, R.; Kempf, T.; Schnölzer, M.; Meyer, P.; et al. Drosophila Spag is the homolog of RNA polymerase II-associated protein 3 (RPAP3) and recruits the heat shock proteins 70 and 90 (Hsp70 and Hsp90) during the assembly of cellular machineries. J. Biol. Chem. 2014, 289, 6236-6247. [CrossRef] [PubMed]

45. Henri, J.; Chagot, M.E.; Bourguet, M.; Abel, Y.; Terral, G.; Maurizy, C.; Aigueperse, C.; Georgescauld, F.; Vandermoere, F.; Saint-Fort, R.; et al. Deep structural analysis of RPAP3 and PIH1D1, two components of the HSP90 co-chaperone R2TP complex. Structure 2018, 26, 1196-1209. [CrossRef]

46. Martino, F.; Pal, M.; Muñoz-Hernández, H.; Rodríguez, C.F.; Núñez-Ramírez, R.; Gil-Carton, D.; Degliesposti, G.; Skehel, J.M.; Roe, S.M.; Prodromou, C.; et al. RPAP3 provides a flexible scaffold for coupling HSP90 to the human R2TP co-chaperone complex. Nat. Commun. 2018, 9, 1501. [CrossRef]

47. Stolc, V.; Samanta, M.P.; Tongprasit, W.; Marshall, W.F. Genome-wide transcriptional analysis of flagellar regeneration in Chlamydomonas reinhardtii identifies orthologs of ciliary disease genes. Proc. Natl. Acad. Sci. USA 2005, 102, 3703-3707. [CrossRef]

48. Zhao, L.; Yuan, S.; Cao, Y.; Kallakuri, S.; Li, Y.; Kishimoto, N.; DiBella, L.; Sun, Z. Reptin/Ruvbl2 is a Lrrc6/Seahorse interactor essential for cilia motility. Proc. Natl. Acad. Sci. USA 2013, 110, 12697-12702. [CrossRef]

49. Dafinger, C.; Rinschen, M.M.; Borgal, L.; Ehrenberg, C.; Basten, S.G.; Franke, M.; Höhne, M.; Rauh, M.; Göbel, H.; Bloch, W.; et al. Targeted deletion of the AAA-ATPase Ruvbl1 in mice disrupts ciliary integrity and causes renal disease and hydrocephalus. Exp. Mol. Med. 2018, 50, 75. [CrossRef]

50. Tammana, D.; Tammana, T.V.S. Human DNA helicase, RuvBL1 and its Chlamydomonas homologue, CrRuvBL1 plays an important role in ciliogenesis. Cytoskeleton 2017, 74, 251-259. [CrossRef]

51. Yamamoto, R.; Hirono, M.; Kamiya, R. Discrete PIH proteins function in the cytoplasmic preassembly of different subsets of axonemal dyneins. J. Cell Biol. 2010, 190, 65-71. [CrossRef] 
52. Yamaguchi, H.; Oda, T.; Kikkawa, M.; Takeda, H. Systematic studies of all PIH proteins in zebrafish reveal their distinct roles in axonemal dynein assembly. eLife 2018, 7, e36979. [CrossRef] [PubMed]

53. Liu, G.; Wang, L.; Pan, J. Chlamydomonas WDR92 in association with R2TP-like complex and multiple DNAAFs to regulate ciliary dynein preassembly. J. Mol. Cell Biol. 2019, 11, 770-780. [CrossRef] [PubMed]

54. Patel-King, R.S.; Sakato-Antoku, M.; Yankova, M.; King, S.M. WDR92 is required for axonemal dynein heavy chain stability in cytoplasm. Mol. Biol. Cell. 2019, 30, 1834-1845. [CrossRef] [PubMed]

55. Zur-Lage, P.; Stefanopoulou, P.; Styczynska-Soczka, K.; Quinn, N.; Mali, G.; von Kriegsheim, A.; Mill, P.; Jarman, A.P. Ciliary dynein motor preassembly is regulated by Wdr92 in association with HSP90 co-chaperone, R2TP. J. Cell Biol. 2018, 217, 2583-2598. [CrossRef]

56. Hartill, V.L.; van de Hoek, G.; Patel, R.; Little, M.P.; Watson, C.M.; Berry, I.R.; Shoemark, A.; Abdelmottaleb, D.; Parkes, E.; Bacchelli, C.; et al. DNAAF1 links HEATR laterality with the AAA+ ATPase RUVBL1 and ciliary intraflagellar transport. Hum. Mol. Genet. 2018, 27, 529-545. [CrossRef]

57. Loges, N.T.; Olbrich, H.; Becker-Heck, A.; Haffner, K.; Heer, A.; Reinhard, C.; Schmidts, M.; Kispert, A.; Zariwala, M.A.; Leigh, M.W.; et al. Deletions and point mutations of LRRC50 cause primary ciliary dyskinesia due to dynein arm defects. Am. J. Hum. Genet. 2009, 85, 883-889. [CrossRef]

58. Cho, K.J.; Noh, S.H.; Han, S.M.; Choi, W.I.; Kim, H.Y.; Yu, S.; Lee, J.S.; Rim, J.H.; Lee, M.G.; Hildebrandt, F.; et al. ZMYND10 stabilizes intermediate chain proteins in the cytoplasmic pre-assembly of dynein arms. PLoS Genet. 2018, 14, e1007316. [CrossRef]

59. Boulon, S.; Pradet-Balade, B.; Verheggen, C.; Molle, D.; Boireau, S.; Georgieva, M.; Azzag, K.; Robert, M.C.; Ahmad, Y.; Neel, H.; et al. HSP90 and its R2TP/Prefoldin-like cochaperone are involved in the cytoplasmic assembly of RNA polymerase II. Mol. Cell 2010, 39, 912-924. [CrossRef]

60. Inoue, M.; Saeki, M.; Egusa, H.; Niwa, H.; Kamisaki, Y. PIH1D1, a subunit of R2TP complex, inhibits doxorubicin-induced apoptosis. Biochem. Biophys. Res. Commun. 2010, 403, 340-344. [CrossRef]

61. Patel-King, R.S.; King, S.M. A prefoldin-associated WD-repeatprotein (WDR92) is required for the correct architectural assembly of motile cilia. Mol. Biol. Cell 2016, 27, 1204-1209. [CrossRef]

62. Itsuki, Y.; Saeki, M.; Nakahara, H.; Egusa, H.; Irie, Y.; Terao, Y.; Kawabata, S.; Yatani, H.; Kamisaki, Y. Molecular cloning of novel Monad binding protein containing tetratricopeptide repeat domains. FEBS Lett. 2008, 582, 2365-2370. [CrossRef] [PubMed]

63. Maurizy, C.; Quinternet, M.; Abel, Y.; Verheggen, C.; Santo, P.E.; Bourguet, M.; Paiva, A.C.F.; Bragantini, B.; Chagot, M.E.; Robert, M.C.; et al. The RPAP3-Cterminal domain identifies R2TP-like quaternary chaperones. Nat. Commun. 2018, 9, 2093. [CrossRef] [PubMed]

64. Chagot, M.E.; Dos Santos Morais, R.; Dermouche, S.; Lefebvre, D.; Manival, X.; Chipot, C.; Dehez, F.; Quinternet, M. Binding properties of the quaternary assembly protein SPAG1. Biochem. J. 2019, 476, 1679-1694. [CrossRef] [PubMed]

65. Horani, A.; Ustione, A.; Huang, T.; Firth, A.L.; Pan, J.; Gunsten, S.P.; Haspel, J.A.; Piston, D.W.; Brody, S.L. Establishment of the early cilia preassembly protein complex during motile ciliogenesis. Proc. Natl. Acad. Sci. USA 2018, 115, E1221-E1228. [CrossRef]

66. Cloutier, P.; Poitras, C.; Durand, M.; Hekmat, O.; Fiola-Masson, É.; Bouchard, A.; Faubert, D.; Chabot, B.; Coulombe, B. R2TP/Prefoldin-like component RUVBL1/RUVBL2 directly interacts with ZNHIT2 to regulate assembly of U5 small nuclear ribonucleoprotein. Nat. Commun. 2017, 8, 15615. [CrossRef]

67. Dong, F.; Shinohara, K.; Botilde, Y.; Nabeshima, R.; Asai, Y.; Fukumoto, A.; Hasegawa, T.; Matsuo, M.; Takeda, H.; Shiratori, H.; et al. Pih1d3 is required for cytoplasmic preassembly of axonemal dynein in mouse sperm. J. Cell Biol. 2014, 204, 203-213. [CrossRef]

68. Chen, Y.; Zhao, M.; Wang, S.; Chen, J.; Wang, Y.; Cao, Q.; Zhou, W.; Liu, J.; Xu, Z.; Tong, G.; et al. A novel role for DYX1C1, a chaperone protein for both Hsp70 and Hsp90, in breast cancer. J. Cancer Res. Clin. Oncol. 2009, 135, 1265-1276. [CrossRef]

69. Miao, C.; Jiang, Q.; Li, H.; Zhang, Q.; Bai, B.; Bao, Y.; Zhang, T. Mutations in the motile cilia gene DNAAF1 are associated with neural tube defects in humans. G3 2016, 6, 3307-3316. [CrossRef]

70. Liu, Y.; Chen, W.; Gaudet, J.; Cheney, M.D.; Roudaia, L.; Cierpicki, T.; Klet, R.C.; Hartman, K.; Laue, T.M.; Speck, N.A.; et al. Structural basis for recognition of SMRT/N-CoR by the MYND domain and its contribution to AML1/ETO's activity. Cancer Cell 2007, 11, 483-497. [CrossRef]

71. McClintock, T.S.; Glasser, C.E.; Bose, S.C.; Bergman, D.A. Tissue expression patterns identify mouse cilia genes. Physiol. Genom. 2008, 32, 198-206. [CrossRef] 
72. Kobayashi, D.; Asano-Hoshino, A.; Nakakura, T.; Nishimaki, T.; Ansai, S.; Kinoshita, M.; Ogawa, M.; Hagiwara, H.; Yokoyama, T. Loss of zinc finger MYND-type containing 10 (zmynd10) affects cilia integrity and axonemal localization of dynein arms, resulting in ciliary dysmotility, polycystic kidney and scoliosis in medaka (Oryzias latipes). Dev. Biol. 2017, 430, 69-79. [CrossRef] [PubMed]

73. Kurkowiak, M.; Ziętkiewicz, E.; Greber, A.; Voelkel, K.; Wojda, A.; Pogorzelski, A.; Witt, M. ZMYND10-mutation analysis in slavic patients with primary ciliary dyskinesia. PLoS ONE 2016, 11, e0148067. [CrossRef] [PubMed]

74. Mali, G.R.; Yeyati, P.L.; Mizuno, S.; Dodd, D.O.; Tennant, P.A.; Keighren, M.A.; Zur Lage, P.; Shoemark, A.; Garcia-Munoz, A.; Shimada, A.; et al. ZMYND10 functions in a chaperone relay during axonemal dynein assembly. eLife 2018, 7, e34389. [CrossRef] [PubMed]

75. Guo, Z.; Chen, W.; Huang, J.; Wang, L.; Qian, L. Clinical and genetic analysis of patients with primary ciliary dyskinesia caused by novel DNAAF3 mutations. J. Hum. Genet. 2019, 64, 711-719. [CrossRef] [PubMed]

76. Fassad, M.R.; Shoemark, A.; le Borgne, P.; Koll, F.; Patel, M.; Dixon, M.; Hayward, J.; Richardson, C.; Frost, E.; Jenkins, L.; et al. C11orf70 mutations disrupting the intraflagellar transport-dependent assembly of multiple axonemal dyneins cause primary ciliary dyskinesia. Am. J. Hum. Genet. 2018, 102, 956-972. [CrossRef]

77. Höben, I.M.; Hjeij, R.; Olbrich, H.; Dougherty, G.W.; Nöthe-Menchen, T.; Aprea, I.; Frank, D.; Pennekamp, P.; Dworniczak, B.; Wallmeier, J.; et al. Mutations in C11orf70 cause primary ciliary dyskinesia with randomization of left/right body asymmetry due to defects of outer and inner dynein arms. Am. J. Hum. Genet. 2018, 102, 973-984. [CrossRef]

78. Zietkiewicz, E.; Bukowy-Bieryllo, Z.; Rabiasz, A.; Daca-Roszak, P.; Wojda, A.; Voelkel, K.; Rutkiewicz, E.; Pogorzelski, A.; Rasteiro, M.; Witt, M. CFAP300: Mutations in Slavic patients with primary ciliary dyskinesia and a role in ciliary dynein arms trafficking. Am. J. Respir. Cell Mol. Biol. 2019, 61, 440-449. [CrossRef]

79. Austin-Tse, C.; Halbritter, J.; Zariwala, M.A.; Gilberti, R.M.; Gee, H.Y.; Hellman, N.; Pathak, N.; Liu, Y.; Panizzi, J.R.; Patel-King, R.S.; et al. Zebrafish ciliopathy screen plus human mutational analysis identifies C21orf59 and CCDC65 defects as causing primary ciliary dyskinesia. Am. J. Hum. Genet. 2013, 93, 672-686. [CrossRef]

80. Lucas, J.S.; Burgess, A.; Mitchison, H.M.; Moya, E.; Williamson, M.; Hogg, C.; National PCD Service, UK. Diagnosis and management of primary ciliary dyskinesia. Arch. Dis. Child. 2014, 99, 850-856. [CrossRef]

81. Boon, M.; Wallmeier, J.; Ma, L.; Loges, N.T.; Jaspers, M.; Olbrich, H.; Dougherty, G.W.; Raidt, J.; Werner, C.; Amirav, I.; et al. MCIDAS mutations result in a mucociliary clearance disorder with reduced generation of multiple motile cilia. Nat. Commun. 2014, 5, 4418. [CrossRef]

82. Reiter, J.F.; Leroux, M.R. Genes and molecular pathways underpinning ciliopathies. Nat. Rev. Mol. Cell Biol. 2017, 18, 533-547. [CrossRef] [PubMed]

83. Knowles, M.R.; Zariwala, M.; Leigh, M. Primary Ciliary Dyskinesia. Clin. Chest. Med. 2016, 37, 449-461. [CrossRef] [PubMed]

84. Mitchison, H.M.; Valente, E.M. Motile and non-motile cilia in human pathology: From function to phenotypes. J. Pathol. 2017, 241, 294-309. [CrossRef] [PubMed]

85. Hirokawa, N.; Tanaka, Y.; Okada, Y. Cilia, KIF3 molecular motor and nodal flow. Curr. Opin. Cell Biol. 2012, 24, 31-39. [CrossRef] [PubMed]

(C) 2019 by the authors. Licensee MDPI, Basel, Switzerland. This article is an open access article distributed under the terms and conditions of the Creative Commons Attribution (CC BY) license (http://creativecommons.org/licenses/by/4.0/). 